\section{Guías de medicina ambulatoria y hospitalaria deUNIFESP/EPM: Psiquiatría}

\author{
Autores: Escuela Paulista de Medicina, \\ Universidad Federal del Estado de \\ Editor de \\ Sao Paulo, Brasil. \\ la serie: Nestor Schor \\ Editorial: Editora M anoleLtda. Brasil, 2002.
}

Este es un manual de Psiquiatría editado por Nestor Schor, pro-rector de postgrado e investigación, y profesor titular en el departamento de M edicina en la muy prestigiada Escuela Paulista de Medicina (UNIFESP). La coordinación del manual estuvo a cargo de cuatro académicos del correspondiente departamento de Psiquiatría (Jair de Jesús Mari, Dense Razzouk, María Fernanda Tourinho Peres y José Alberto del Porto), contando con la colaboración adicional de veintiséis autores para la elaboración de 21 importantes capítulos de la materia, presentados en 256 páginas.

En la elaboración del presente manual se ha escogido los temas de mayor importancia y actualidad en la práctica clínica de la Psiquiatría ambulatoria y de hospitalización, tratándolos en forma sistematizada, resumida y actualizada. Su presentación es muy didáctica para los estudiantes de pre-grado y de positiva ayuda para los psiquiatras jóvenes en formación (internos, residentes, postítulos), así como de evidente utilidad práctica como ayuda memoria y actualización, para los psiquiatras ya formados, sujetos a la educación continua. Además, este manual también puede servir para orientar al clínico general destacado en la atención primaria extra-hospitalaria, cuando tenga que enfrentar patología psiquiátrica de urgencia.

A partir de una revisión epidemiológica, se continúa con los principales síndromes neuróticos, seguido de diversos trastornos de conducta relacionados con abuso de sustancias y drogas, algunos trastornos de la alimentación, principales síndromes psicóticos y una revisión actualizada de los principales fármacos utilizados en Psiquiatría.

La orientación de los autores es amplia, abarcativa y práctica. La presentación está muy bien sistematizada y resumida. Se puede considerar de mucha utilidad para, ubicar al clínico en situaciones de emergencias.

Si cabe una reflexión crítica, podría parecer que ciertos temas clínicos más difíciles de abordar (como son los trastornos graves de personalidad, las perversiones, la patología psicosomática, los trastornos de la vida sexual, los problemas de pareja y de familia), al no estar suficientemente considerados pudieran parecer menos importantes o más graves. Igualmente, la mención sumaria de diferentes técnicas y métodos psicoterapéuticos, podría aparecer a veces como un saludo a la bandera que arriesga no ponderar -en comparación con el empleo de los psicofármacoslas dificultades y complejidades de dicha materia. Pero estas consideraciones, de ninguna manera disminuyen el mérito de la presente "Guía" Psiquiátrica. Sería muy útil traducirla al castellano para facilitar su lectura al difundirla en nuestro medio. 